\title{
Incidence of contrast induced nephropathy among patients undergoing coronary interventions
}

\author{
Ravi Kiran C. ${ }^{1}$, Muralidhar G. ${ }^{2 *}$, Ravikanth K. ${ }^{3}$, Chandra T. 4 \\ DOI: https://doi.org/10.17511/ijmrr.2019.i06.01
}

\footnotetext{
${ }^{1}$ Ch Veerendra Ravi Kiran, Assistant Professor, Department of General Medicine, GSL Medical College, Rajahmundry, Andhra Pradesh, India.

2* G Muralidhar, Assistant Professor, Department of Medical Oncology, GSL Medical College, Rajahmundry, Andhra Pradesh, India.

${ }^{3}$ K. R. Ravikanth, Resident, Department of General Medicine, GSL Medical College, Rajahmundry, Andhra Pradesh, India.

4 T Jaya Chandra, Scientist Incharge, Central Research laboratory, GSL Medical College, Rajahmundry, Andhra Pradesh, India.
}

Background: Contrast media (CM) used during diagnostic and therapeutic percutaneous procedures is eliminated by the kidneys. A study has been planned to find the adverse effects of contrast agents on renal system. Methods: This was a hospital based cross sectional study, conducted in the department of general medicine, GSL Medical College. Individuals $>25$ age, both gender with heamoglobin concentration of $>10 \mathrm{mg} / \mathrm{dl}$ were included. Exclusion criteria was also followed. Iodixanol or iohexol was used, administered at the rate of $80-100 \mathrm{ml}$ per participants. Blood samples were collected standard techniques before the procedure and 48 hours after the procedure for serum creatinine levels. Renal function was assessed by estimating creatinine clearance using the Cockcroft-gault formulae. As per national kidney foundation participants were divided in to 4 categories normal, mildly impaired, moderately impaired and severely impaired renal function; p $<0.05$ was considered as statistically significant. Results: Out of 80 study subjects, CIN was increased with age, identified in $37.9 \%$ diabetics, $48.3 \%$ smokers, $41.4 \%$ alcoholics; statistically there was no significant difference. In the normal category $34.5 \%, 41.4 \%$ in mild category, $24.1 \%$ in moderate renal dysfunction category developed CIN, association was statistically significant. Conclusions: With these findings we conclude that overall increase in the incidence of CIN with age and no influence of gender as well as conditions like diabetes and hypertension.

Keywords: Contrast media, Contrast induced nephropathy

Corresponding Author

G Muralidhar, Assistant Professor, Department of Medical Oncology, GSL Medical College, Rajahmundry, Andhra Pradesh, India. Email: gslcentralresearchlab@gmail.com
How to Cite this Article To Browse

Kiran CVR, Muralidhar G, Ravikanth KR, Chandra TJ. Incidence of contrast induced nephropathy among patients undergoing coronary interventions. Int J Med Res Rev. 2019;7(6):443-446.

Available From

https://ijmrr.medresearch.in/index.php/ijmrr/article/ view/1092

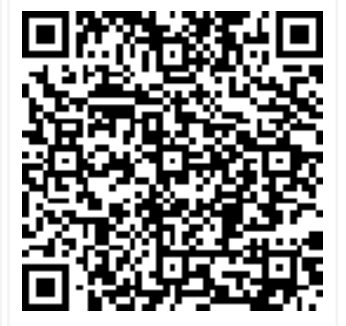

Manuscript Received 2019-10-10

Conflict of Interest No
Review Round 1 2019-10-20

Funding

$\mathrm{Nil}$
Review Round 2 2019-10-25

Ethical Approval Yes
Review Round 3

Accepted 2019-11-01

Plagiarism X-checker $6 \%$

Note

(c) 2019 by Ch Veerendra Ravi Kiran, G Muralidhar, K. R. Ravikanth, T Jaya Chandra and Published by Siddharth Health Research and Social Welfare Society. This is an Open Access article licensed under a Creative Commons Attribution 4.0 International icense https://creativecommons.org/licenses/by/4.0/ unported [CC BY 4.0]. 


\section{Background}

Under normal physiological conditions, the volume and composition of body fluids vary within narrow limits due to proper function of kidneys. They also sub-serve a host of metabolic and endocrine functions. Failure of renal function results ultimately in alterations of milieu interior that affects every system in the body. Acute kidney injury (AKI) or acute renal failure (ARF) is defined as an abrupt or rapid decline in renal filtration function. Nearly all of the contrast media (CM) used during diagnostic and therapeutic percutaneous procedures is eliminated by the kidneys. The concentration achieved in the renal tubular system is less than or equal to the concentration achieved in plasma and approaches less than or equal to injected solution [1] so it is not surprising that CM could be a cause of AKI. Contrast induced nephropathy (CIN) is now a well recognized form of iatrogenic AKI causing acute detoriation of kidney function with risk of chronic kidney disease are at increased risk of death [2-6]. Once the other causes of AKI have been excluded this detoriation in renal function is usually attributed to exposure of contrast material and is termed as contrast induced nephropathy (CIN). Fortunately, most of the cases of CIN are self-limited and kidney function returns to normal in 2 weeks after exposure to contrast media. CM is increasingly used in both diagnostic and therapeutic procedures in the modern era of interventional cardiology. This results in increasing incidence of iatrogenic renal function impairment.

CM makes the arteries radio opaque and help in viewing with fluoroscopy. The ideal contrast medium would achieve a very high concentration in tissues without producing any adverse effects. Unfortunately, this has not been possible and so far, all CM have adverse effects. Kidneys being the primary portal of excreting waste products of metabolism and foreign chemicals. With this, a study on incidence and adverse effects of contrast agents on renal function based on serum creatinine and creatinine clearance in patients without a preexisting renal disease.

\section{Methods}

Study design: Hospital based cross sectional study

Sample size: Random sampling was considered during the study period; 80 subjects who underwent elective angiography/angiogram were included in the study.
Settings: Study was conducted in the department of general medicine, GSL Medical college with the association of department of cardiology, central diagnostic laboratory and central research laboratory.

Study period: Two years; September 2012 to august 2014

IEC approval: Study was approved by ethical clearance committee.

Inclusion criteria: Individuals $>25$ age, both gender with heamoglobin concentration of > $10 \mathrm{gm} / \mathrm{dl}$ were included.

Exclusion criteria: The Individuals with intravenous administration of $\mathrm{CM}$ with in the previous seven days, individuals on aminoglycosides, nephrotoxic drug therapy, nonsteroidal anti-inflammatory therapy with in previous seven days and history allergic reactions to CM, patients on dialysis and patients with previous contrast exposure were not included. Iodixanol or iohexol is the most commonly used $\mathrm{CM}$ in the present study both are low osmolar non-ionic CM.

All patients received the $80-100 \mathrm{ml} \mathrm{CM}$. Dose of CM, angioplasty technique and supportive pharmacological therapies were decided by the interventional cardiologist. Blood samples were collected by the standard phlebotomy techniques before the procedure and 48 hours after the procedure for serum creatinine levels for estimation by modified jaffe's method by semi auto analyser.

As per the definition of CIN difference in the creatinine levels before the procedure and 48 hours after the procedure were calculated. Percentage increase in the cretinine levels were calculated based on difference on the creatinine levels/cretinine levels before procedure X100. Renal function was assessed by estimating creatinine clearance $(\mathrm{CCL})$ using the Cockcroft-gault formula $[7,8]$. As per national kidney foundation $[9,10]$ by considering the $\mathrm{CCL}$ values, the participants were divided in to 4 categories normal, mildly impaired, moderately impaired and severely impaired renal function.

Statistical analysis was done by using SPSS. Student paired $t$ test was performed for comparison of mean of deferent groups. Chi-Square test was performed to assess the association among deferent categorical variables. For all statistical analysis $\mathrm{p}<0.05$ was considered as statistically significant. 


\section{Results}

Total 80 study subjects were included in this study; in this $48(60 \%)$ were male and $32(40 \%)$ were female participants. The male female ratio in this study was 1.5 , Gender wise CIN developed ratio was 1.9.

Age wise, highest number (33) of participants were included in 51-60 years age group followed by 4150 years group (2.5\%), 61-70 years group $(18.8 \%), \quad 31-40$ years group $(10 \%)$ and less number $(7.5 \%)$ in $71-80$ years age group. When CIN was considered, highest (31\%) in 41-50, 51-60 years age group, respectively. Age wise, CIN was increased with age (Table 1 ). When the comorbid conditions were considered, $37.9 \%$ diabetics, $48.3 \%$ smokers, $41.4 \%$ alcoholics developed CIN; statistically there was no significant difference.

Table-1: Incidence of CIN according to the age; $n(\%)$.

\begin{tabular}{|l|l|l|}
\hline \multicolumn{1}{|c|}{ Age in years } & \multicolumn{1}{|c|}{ Number of study participants } & \multicolumn{1}{c|}{ CIN } \\
\hline $31-40$ & $8(10)$ & $1(3.4)$ \\
\hline $41-50$ & $18(22.5)$ & $9(31)$ \\
\hline $51-60$ & $33(41.2)$ & $9(31)$ \\
\hline $61-70$ & $15(18.8)$ & $8(27.6)$ \\
\hline $71-80$ & $6(7.5)$ & $2(6.9)$ \\
\hline
\end{tabular}

In the normal category 10 (34.5\%), mild category $12(41.4 \%)$, moderate renal dysfunction category $67(24.1 \%)$ developed CIN. There were no study subjects in the fourth category i.e severe renal dysfunction. When the CM effect was correlated with renal function tests, the mean serum creatinine levels were $1.00 \pm 0.19,1.21 \pm 0.34$ respectively in pre and post angio groups; statistically there was significant difference. Whereas the mean creatinine clearance value was $81.98 \pm 21.5,68.36 \pm 22.01$ respectively in pre and post angio groups; statistically there was significant difference (Table 2).

Table-2: Effect of CM on renal function tests; Mean + standard deviation

\begin{tabular}{|l|l|l|l|}
\hline \multicolumn{1}{|c|}{ Study variables } & Pre angiography & Post angiography & P value \\
\hline Serum creatinine & $1.00 \pm 0.19$ & $1.21 \pm 0.34$ & $<0.000$ \\
\hline Creatinine clearance & $81.98 \pm 21.5$ & $68.36 \pm 22.01$ & $<0.000$ \\
\hline
\end{tabular}

\section{Discussion}

CIN is an iatrogenic disorder with high morbidity and mortality with a high incidence in elderly, diabetics, and patients with pre-existing renal dysfunction.
Luckily CIN is a transient process and most patients recover within two weeks. Age is an independent risk factor for CIN, established in many trials. In a study by Roxana mehran et al., concluded that elderly age $>75$ is an important individual predictor for CIN [11].

Similar results were observed in a study named by Gussenhoven MJ and Ravensbergen et al [12] and Sanjib kumar Sharma et al [13]; both the studies reported significant difference with age $(p=0.01)$. The reasons for higher risk to develop CIN in elderly were not studied specifically. Probably it may multifactorial such as age-related changes in renal function such as diminished glomerular filtration rate, tubular secretion, concentrating ability so on.

Similar findings were reported in this study also; age wise, highest number (33) of participants were included in 51-60 years age group followed by $41-$ 50 years group $(2.5 \%), 61-70$ years group $(18.8 \%), \quad 31-40$ years group $(10 \%)$ and less number $(7.5 \%)$ in $71-80$ years age group. When CIN was considered, highest (31\%) in 41-50, 51-60 years age group, respectively. Age wise, CIN was increased with age (Table 1 ). Whereas the mean age of patients with CIN was reported to be $61.40 \pm 13.86$ years by Maneesha et al [14].

In this report, gender wise, the incidence of CIN was $34.5 \%$ and $65.5 \%$ respectively in male and female; statistically the difference was not significant $(P>0.05)$. However, it was reported that gender has no effect on CIN [15]. Whereas in this study, due to a greater number of male participants might be the cause for higher incidence. Diabetes is an important independent predictor, increase the risk of CIN.

In present study, $37.9 \%$ (11 out of 34 diabetics) developed CIN. Whereas CIN was reported to be $20 \%$ by Omer to prak and Mustafa cirit et al; $11.4 \%$ in pre diabetics and $5.5 \%$ in subjects without diabetes [15]. No diabetic study subjects had an established renal failure before the procedure in this study, all of them had well maintained glycemic status. Similar findings were showed in Roxana Meharan et al., [11] report. However, Sanjibkumar Sharma et al., [13] reported just $12.5 \%$ only.

In this study, the CM effect was correlated with renal function tests, the mean serum creatinine levels were $1.00 \pm 0.19,1.21 \pm 0.34$ respectively in pre and post angio groups; statistically there was significant difference. 
Whereas the mean creatinine clearance value was $81.98 \pm 21.5,68.36 \pm 22.01$ respectively in pre and post angio groups; statistically there was significant difference (Table 2). The mean serum creatinine was reported to be $1.53 \pm 0.4 \mathrm{mg} / \mathrm{dl}$ and the eGFR was $46.47 \pm 8.9 \mathrm{ml} / \mathrm{mt}$. Previous studies show that patient demographics like older patients, anemia, the presence of diabetes mellitus, a low ejection fraction, usage of loop diuretics and procedural characteristics like intra procedure hypotension, increased contrast volume confer a significant risk of CIN [16-18]. In this study, $48.3 \%$ smokers and $41.4 \%$ alcoholics developed CIN. But the exact role of smoking and alcohol is not established. Probably smoking may add to incidence by increasing the oxidative stress. Higher $(63 \%)$ rate of CIN was reported among smokers by $M$ Akhataruzzaman et al., [19] report, but the exact predictor for CIN could not be established. The final end point of the present study was to evaluate rise in serum creatinine or decrease in creatinine clearance. Minimum and maximum serum creatinine values were $0.5 \mathrm{mg} / \mathrm{dl}$ and $1.2 \mathrm{mg} / \mathrm{dl}$ in pre angio and the levels were 0.6 and $2.6 \mathrm{mg} / \mathrm{dl}$ in post angio. Similarly, the pre angio minimum and maximum values of creatinine clearance were 44.08 and 143 $\mathrm{ml} / \mathrm{min}$ and the levels were 28 and $143 \mathrm{ml} / \mathrm{min}$ in post angio; statistically the difference were significant. When these values were correlated with CIN, the rate of incidence was $36.2 \%$ (29) for serum creatinine and statistically the difference was significant $(p=0.0001)$. But Priya SV et al reported $0.6 \%$ CIN only [20].

\section{Limitations}

Single centric research and small sample size are the limitations of this research.

\section{Conclusion}

With these findings we conclude that overall increase in the incidence of CIN with age and no influence of gender as well as conditions like diabetes and hypertension. But studies on large sample size with additional comorbid conditions is recommended for better conclusion.

\section{What the study adds to the existing knowledge?}

Overall increase in the incidence of CIN with age and no influence of gender as well as conditions like diabetes and hypertension

\section{Author's contribution}

Dr. Ch Veerendra Ravi Kiran: Study design, data analysis, paper writing.

Dr. G. Muralidhar: Study design, paper writing.

Dr. K.R. Ravikanth: Bench work, data analysis.

Dr. T Jaya Chandra: Data analysis, paper writing.

\section{Reference}

01. Katzberg RW. Urography into the 21st centurynew contrast media, renal handling, imaging characteristics, and nephrotoxicity. Radiol. 1997;204(2)297-312.

doi: 10.1148/radiology.204.2.9240511 [Crossref]

02. Weisbord SD, Chen $H$, Stone RA, Kip KE, Fine MJ, Saul MI, et al. Associations of increases in serum creatinine with mortality and length of hospital stay after coronary angiography. J Am Soc Nephrol. 2006;17(10)2871-2877. doi: 10.1681/ASN.2006030301 [Crossref]

03. McCullough P. Outcomes of contrast-induced nephropathy- experience in patients undergoing cardiovascular intervention. Catheter Cardiovasc Interv. 2006;67(3)335-343.

doi: $10.1002 /$ ccd.20658 [Crossref]

04. Persson PB. Contrast-induced nephropathy. Eur Radiol. 2005;15(4)D65-D69.

doi: [Article] [Crossref]

05. McCullough PA, Adam A, Becker CR, Davidson C, Lameire N, Stacul F, et al. Epidemiology and prognostic implications of contrast-induced nephropathy. Am J Cardiol. 2006;98(6)5-13. doi: [Article] [Crossref]

06. McCullough PA, Wolyn R, Rocher LL, Levin RN, O'Neill WW. Acute renal failure after coronary intervention- incidence, risk factors, and relationship to mortality. Am J Med. $1997 ; 103(5) 368-375$.

doi: $10.1016 /$ s0002-9343(97)00150-2 [Crossref]

07. Cockcroft DW, Gault MH. Prediction of creatinine clearance from serum creatinine. Nephron. $1976 ; 16(1) 31-41$.

doi: $10.1159 / 000180580$ [Crossref] 
08. Gault MH, Longerich LL, Harnett JD, Wesolowski C. Predicting glomerular function from adjusted serum creatinine. Nephron. 1992;62(3)249-56. doi: 10.1159/000187054 [Crossref]

09. Kopple JD. National kidney foundation K/DOQI clinical practice guidelines for nutrition in chronic renal failure. Am J Kidney Dis. 2001;37(2)S66-S70.

doi: 10.1053/ajkd.2001.20748 [Crossref]

10. National Kidney Foundation. K/DOQI clinical practice guidelines for chronic kidney disease: evaluation, classification, and stratification. Am J Kidney Dis. 2002;39(2 Suppl 1)S1-266.

[Crossref]

11. Mehran R, Aymong ED, Nikolsky E, Lasic $Z$, Iakovou I, Fahy $M$ et al. A simple risk score for prediction of contrast-induced nephropathy after percutaneous coronary interventiondevelopment and initial validation. J Am Coll Cardiol. 2004;44(7)1393-1399.

doi: 10.1016/j.jacc.2004.06.068 [Crossref]

12. Gussenhoven MJ, Ravensbergen J, van Bockel JH, Feuth JD, Aarts JC. Renal dysfunction after angiography- a risk factor analysis in patients with peripheral vascular disease. J Cardiovasc Surg (Torino). 1991;32(1)81-86.

[Crossref]

13. Sharma SK, Dubey L, Laudary S, Dhungel S, Ghimire $M$, Pahari $B$, et al. Incidence and predictors of contrast induced nephropathy after coronary intervention at College of Medical Sciences Teaching Hospital, Bharatpur. Nepalese Heart J. 2014;11(1)3-11.

doi: $10.3126 /$ njh.v11i1.10975 [Crossref]

14. Maneesha sasidharan, E JAMES, JCM Prasad. Incidence and predictors of contrast-induced nephropathy in patients undergoing percutane ous coronary interventions at an Indian tertiary care center. Indian J Pharm Sci. 2019;81(4)72936. [Crossref]

15. Toprak O, Cirit M, Yesil M, Bayata S, Tanrisev M, Varol $U$, et al. Impact of diabetic and prediabetic state on development of contrastinduced nephropathy in patients with chronic kidney disease. Nephrol Dial Transplant. 2007;22(3)819-826.

doi: $10.1093 / \mathrm{ndt} / \mathrm{gfl} 636$ [Crossref]
16. Valappil SP, Kunjukrishnapillai S, Iype M, Koshy AG, Viswanathan S, Gupta PN, et al. Predictors of contrast induced nephropathy and the applicability of the Mehran risk score in high risk patients undergoing coronary angioplasty-A study from a tertiary care center in South India. Indian Heart J. 2018;70(3)399-404. doi: 10.1016/j.ihj.2017.08.018 [Crossref]

17. Mehran R, Aymong ED, Nikolsky E, Lasic Z, Iakovou I, Fahy M, et al. A simple risk score for prediction of contrast-induced nephropathy after percutaneous coronary interventiondevelopment and initial validation. J Am Coll Cardiol. 2004;44(7)1393-1399. doi: $10.1016 /$ j.jacc.2004.06.068 [Crossref]

18. Evola S, Lunetta M, Macaione F, Fonte G, Milana $G$, Corrado $E$, et al. Risk factors for contrast induced nephropathy- A study among Italian patients. Ind Heart J. 2012;64(5)484-491.

doi: 10.1016/j.ihj.2012.07.007 [Crossref]

19. Akhtaruzzaman $M, \quad$ Choudhury $A K$, Khalequzzaman M, Barua SK, Choudhury TA, Hasem $S$, et al. Impact of low hemoglobin on contrast-induced nephropathy after percutaneous coronary intervention. Cardiovas J. $2012 ; 5(1) 30-36$. doi: $10.3329 /$ cardio.v5i1.12226 [Crossref]

20. Priya SV, Jayakumar KP, Jayaprakash VL, George R. Contrast Induced Nephropathy-A study of 850 patients undergoing cardiac catheterization laboratory procedures. Kerala Heart J. $2015 ; 1(1) 14-17$.

[Crossref] 